\title{
SER PROFESSOR, UMA CONSTRUÇÃO EM TRÊS ATOS: FORMAÇÃO, INDUÇÃO E DESENVOLVIMENTO NA CARREIRA
}

\author{
ELISANGELA DA SILVA BERNADO ${ }^{1}$ \\ ORCID: https://orcid.org/0000-0003-3994-0254 \\ KATIA VASCONCELLOS ${ }^{2}$ \\ ORCID: https://orcid.org/0000-0002-2442-1913
}

\begin{abstract}
RESUMO: $\mathrm{O}$ artigo pretende refletir acerca da construção profissional do professor em três momentos, a saber: a formação inicial, a indução nos primeiros anos de exercício profissional e o desenvolvimento por meio da formação contínua. Tais marcos têm repetidamente orientado o percurso da construção da nossa identidade docente. Desse modo, o que apresentaremos é um entretecer de pesquisas realizadas no âmbito da nossa formação em três reflexões, sendo elas: um diálogo sobre a formação inicial docente no Brasil e em Portugal; uma Revisão Sistemática de Literatura sobre a indução na profissão docente e uma reflexão sobre a Formação Contínua de Professores em uma escola de tempo integral. Para a Revisão Sistemática de Literatura (RSL), apoiamo-nos em teóricos como: Nóvoa (1992; 2019); Huberman (2013), Tardif (2000) e Gatti (2010). A pesquisa é de cunho qualitativo e se insere no paradigma interpretativo que apresenta, dentre outras funções primárias, a identificação de conceitos por meio de um grupo de questões teóricas e metodológicas emergentes do processo de investigação. Para o desenvolvimento metodológico, utilizamos diferentes recursos, dentre os quais destacamos: as técnicas de análise documental, a organização de um protocolo que sintetiza os principais argumentos dos teóricos em seus textos e trouxemos à discussão os resultados oriundos da RSL. Como achados da pesquisa, destacamos a necessidade de uma estruturação de tempos e espaços para que aconteçam os encontros formativos, a fim de criarmos momentos de troca que apresentem significados teóricos e práticos na reflexão individual e coletiva do professor.
\end{abstract}

Palavras-chave: Formação Docente, Entrada Profissional, Formação Continuada.

\section{BEING A TEACHER, A CONSTRUCTION IN THREE ACTS: FORMATION,, INDUCTION AND CAREER DEVELOPMENT}

\begin{abstract}
The article aims to reflect about the professional construction of teachers in three moments, namely: initial formation, induction in the first years of professional practice, and development through continuing education. These milestones have repeatedly guided the construction of our teaching identity. In this way, what we will present is an interweaving of research conducted in the scope of our training into three reflections, namely: a dialogue on initial teacher training in Brazil and Portugal; a

\footnotetext{
1 Professora Associada na Universidade Federal do Estado do Rio de Janeiro (UNIRIO). Rio de Janeiro: RJ, Brasil. <efelisberto@yahoo.com.br>

${ }^{2}$ Doutoranda em Ciências da Educação na Universidade de Évora. Portugal. < katiaregi.76@gmail.com> Educação em Revista|Belo Horizonte|v.37|e32800|2021
} 
Systematic Literature Review on induction into the teaching profession; and a reflection on Ongoing Teacher Training in a full-time school. For the Systematic Literature Review (SLR), we rely on theorists such as: Nóvoa (1992; 2019); Huberman (2013), Tardif (2000) and Gatti (2010). The research is qualitative in nature and falls within the interpretive paradigm that presents, among other primary functions, the identification of concepts through a group of theoretical and methodological questions emerging from the research process. For the methodological development, we used different resources, among which we highlight: the document analysis techniques, the organization of a protocol that synthesizes the main arguments of the theorists in their texts, and we brought to discussion the results arising from the RSL. As research findings, we highlight the need to structure the times and spaces for the formative meetings to take place, in order to create moments of exchange that present theoretical and practical meanings in the teacher's individual and collective reflection.

Keywords: Teacher Training, Professional Entry, Continuing Education.

\section{SER DOCENTE, UNA CONSTRUCCIÓN EN TRES ACTOS: FORMACIÓN, INDUCCIÓN Y DESARROLLO PROFESIONAL}

RESÚMEN: Este artículo tiene como objetivo reflexionar sobre la construcción profesional del docente, analizando tres momentos cruciales en este desarrollo, a saber: la formación inicial, la inducción en los primeros años de práctica profesional y, al final, el desarrollo a través de la formación continuada. Estos hitos han guiado reiteradamente el camino hacia la construcción de nuestra identidad docente. Así, lo que presentaremos es un entrelazamiento de investigaciones realizadas en el ámbito de nuestra formación. Tres reflexiones, a saber: un diálogo sobre la inducción docente en Brasil y Portugal. El segundo presenta una Revisión sistemática de la literatura con un resumen de los datos actuales sobre la inducción en la profesión docente. Y la tercera reflexión trae el tema de la formación continua del profesorado en una escuela de tiempo completo. Para la Revisión de Literatura Sistemática (RSL), nos apoyamos en teóricos como: Nóvoa (1992; 2019); Huberman (2013), Tardif (2000), Gatti (2010). La investigación es cualitativa y forma parte del paradigma interpretativo que presenta, entre otras funciones primarias, la identificación de conceptos a través de un conjunto de cuestiones teóricas y metodológicas emergentes del proceso de investigación. Para el desarrollo metodológico se utilizaron diferentes recursos, entre los que destacamos: técnicas de análisis de documentos, la organización de un protocolo que sintetice los principales argumentos de los teóricos en sus textos, y traer a discusión los resultados que surgen de la RSL. Como hallazgos de la investigación, destacamos la necesidad de una completa estructuración de tiempos y espacios para los encuentros formativos y la importancia de escuchar la demanda interna de cada escuela, para crear momentos de intercambio que presenten significados teóricos y prácticos en el individual y colectivo docente.

Palabras clave: Formación del profesorado, Ingreso profesional, Formación continuada. 


\section{INTRODUÇÃO}

Ao realizarmos uma busca simples na internet com o termo Formação Docente, obteremos um número aproximado de 36400000 resultados (0,53 segundos). Desse universo, há de tudo um pouco: cursos, formações, textos, blogs. Tudo isso para ilustrar a dimensão contida na área temática da formação docente. Nós, investigadores acadêmicos, temos um interesse mais restrito e particular em nosso fazer investigativo, que se assenta no desvelar e no compreender como ou quais dinâmicas ocorrem e como elas impactam as vidas profissionais dos professores. Os estudos na área da formação docente têm sido recorrentes e, sob múltiplos aspectos, campos e olhares, produzem pesquisas e novos conhecimentos que auxiliam na discussão de questões de diferentes naturezas e temáticas, ampliando e aprofundando reflexões atuais e pertinentes.

Não é novidade a existência de uma expectativa acerca da melhoria da qualidade da educação e do desenvolvimento social que esse está diretamente ligado à escola, de forma mais geral, e ao professor, de modo mais específico. Tal pressão se expressa nas palavras de Montero (2001, p. 25), no sentido de "Renovar a confiança na educação e atribuir-lhe uma função ambiciosa no desenvolvimento dos indivíduos e das sociedades implica manter, e aumentar, as expectativas sobre o papel que os professores desempenham para a consecução desse objetivo".

Este artigo pretende refletir acerca da construção profissional do professor em três momentos, a saber: a formação inicial, a indução nos primeiros anos de exercício profissional e o desenvolvimento por meio da formação contínua. Tais marcos têm repetidamente orientado o percurso da construção da nossa identidade docente, trazendo reflexões e tensões que permeiam a nossa vidaformação-ação, sem contudo, esgotar tais temáticas. O que defendemos aqui é a identidade e profissionalidade docente como um processo iniciado em sua vida de estudante e, mais especificamente, continuado quando o indivíduo elege a docência enquanto profissão. Esse percurso, via de regra, é marcado por três grandes momentos, quais sejam: a Formação Inicial, como sendo o caminho teórico para a sua habilitação do exercício profissional docente; a Entrada na Profissão (os primeiros anos da prática) e a Formação Continuada, em que há a necessidade de estar sempre aprendendo a aprender e a ensinar de modos diferentes, novos e tão necessários ao desenvolvimento das demais áreas da sociedade e da tecnologia.

Assim sendo, este texto representa uma tessitura entre investigações. Desse modo, o que apresentaremos é um entretecer de pesquisas realizadas no âmbito da nossa formação em três reflexões, sendo elas: um diálogo sobre a formação inicial docente no Brasil e em Portugal apoiado na discussão do aporte normativo acerca da formação de professores dos anos iniciais e de educação de infância; uma Revisão Sistemática de Literatura apresentando um resumo com dados atuais sobre a indução na profissão docente e uma reflexão da temática da Formação Contínua de Professores em uma escola de tempo integral com os dados da pesquisa.

\section{FORMAÇÃO INICIAL: QUESTÕES REFLEXIVAS ACERCA EDUCADOR-PROFESSOR EM PORTUGAL E NO BRASIL}

O professor não ensina apenas o que sabe, ensina o que é.

(Rui Canário, 2007)

Iniciamos nossa reflexão acerca da formação inicial para a docência, destacando os diferentes percursos formativos para a habilitação para a docência dos anos iniciais e da educação de infância em Portugal e no Brasil.

Em Portugal, a Formação do Educador-Professor, a formação dos educadores e professores do primeiro ciclo do ensino básico, denominado educadores de infância (se atuarem no pré escolar) ou educadores-professores (se atuarem no pré escolar e primeiros anos - $1^{\circ} \mathrm{CEB}$ ), enquanto grupo específico, passa a existir, por meio do Decreto-Lei $n^{\circ} 43$ de 2007. Os pressupostos que sustentam essa modificação na habilitação profissional se inserem na seara do Processo de Bolonha no qual o 
argumento que vigora é o da melhoria da educação, sendo indissociável da melhoria da formação profissional. Essa orientação tem sido recorrente e de muitas reuniões originaram-se documentos que reforçaram a importância da educação como canal de transformação social, elevando a qualidade da aprendizagem dos estudantes. Esse movimento, apoiado em outros de organismos e agências multilaterais (UNESCO, 2016), vai ganhar fôlego com a possibilidade de igualar a formação dos países componentes da União Europeia, por meio do reconhecimento da creditação dos diferentes cursos nesses países. Trata-se de não só diminuir a burocracia dos reconhecimentos e equivalências dos cursos e diplomas, mas também de eleger uma base comum que diminua as distâncias formativas, em especial, elevando a formação inicial de professores da licenciatura, que passa a ser o $1^{\circ}$ Ciclo do Ensino Superior para o Mestrado, considerado o $2^{\circ}$ Ciclo do ensino superior.

Em outras palavras, todo professor, a partir do Processo de Bolonha, necessita concluir o $2^{\circ}$ Ciclo de Ensino Superior, alcançando o grau de Mestre para poder lecionar. Apesar dessa reunião ter-se dado em 1999, na cidade de Bolonha, Itália, somente em 2007 foi oficialmente adotada em Portugal. Tal modelo fomentou, nos países europeus, a preocupação em elevar não só a titulação, quando da exigência da obtenção do grau de mestre para o exercício profissional da docência, mas também o conteúdo, organizando, no caso específico português, uma formação de três anos de licenciatura, acrescida de dois anos de mestrado profissional, dentro da área escolhida, onde no término do curso, o formando defende um relatório final, denominado Prática de Ensino Supervisionada (PES) para a conclusão e obtenção de sua titulação.

Em outras palavras, o Decreto Lei no 43/2007 evidencia que é "neste contexto que se promove o alargamento dos domínios de habilitação do docente generalista que passam a incluir a habilitação conjunta para a educação pré-escolar e para o $1^{\circ}$ ciclo do ensino básico ou a habilitação conjunta para os $1^{\circ}$ e $2^{\circ}$ ciclos do ensino básico" (PORTUGAL, 2007).

Como o objetivo de nossa investigação é revelar a forma como se dá a origem desse monodocente tanto pelo viés da lei como pelo olhar da formação, iniciamos por afirmar ser esse um grande desafio, no qual reconhecemos que não há uma história longa ou registros memorísticos que possam corroborar e fornecer material para a constituição de nossa pesquisa. Entretanto, é justamente esse o fato que evidencia o caráter inovador deste estudo e ratificada a sua importância. Nunes e Leal da Costa (2016, p. 122) destacam que:

É importante clarificar que, em Portugal, há um enquadramento legal para a carreira docente, o qual agrega os diferentes níveis de ensino, com exceção para o Ensino Superior. A legislação exige o grau de mestre como habilitação para a docência, quer para educadores de infância, quer para professores. Tal significa uma formação longa, cinco anos, em que três são de Licenciatura em Educação Básica (LEB) e os dois seguintes se cumprem num curso de mestrado profissionalizante com estágio no fim (PES). O caso em análise centra-se no Mestrado em Educação Pré-escolar e $1^{\circ}$ Ciclo do Ensino Básico, um dos cinco percursos possíveis e, talvez, o que é epistemologicamente mais desafiante. 3 Anotamos, ainda, o fato de ser vulgar que os estudantes façam o percurso acadêmico sem interrupções e que a habilitação para a docência coincida com a profissionalização. Assim, os futuros educadores/ professores têm, em geral, entre 22 e 25 anos de idade, obtendo o grau de mestre bastante jovens e com pouca experiência prévia de ensino, ou nenhuma, para além da PES não existindo um período de indução no início da vida profissional.

Uma habilitação para a monodocência, mas que, paradoxalmente, divide o profissional em dois, quando se entra na profissão, não oferece ao profissional a oportunidade de ter um grupo de recrutamento, ao mesmo tempo que a investigação internacional sobre a educação das crianças nos parece apoiar a existência desse perfil, indicando que a educação de infância deve acautelar e reivindicar processos comunicacionais e transições que a monodocência pode favorecer.

Acresce que a compreensão das profissões de educador de infância e de professor do $1^{\circ}$ Ciclo não indica suas sobreposições e a construção socio-histórica dessas profissões também não é coincidente em Portugal. Nossa reflexão perpassa, então, pelas seguintes indagações: Afinal, como será a entrada na profissão desses indivíduos que saem há vários anos de universidades e de escolas superiores de educação? Qual o papel das instituições formadoras? Têm-se tornado, efetivamente, educadoresprofessores no contexto do seu trabalho com crianças? É necessário refletir sobre o valor e a necessidade 
de escutar os professores, realçando uma ecologia dos saberes, compreendida entre os processos e as aprendizagens individuais, singulares e profissionais decorrentes da vida em interação (NÓVOA, 2019; LEAL DA COSTA; SARMENTO, 2018).

No Brasil, a primeira lei específica voltada para a organização da educação brasileira foi a Lei de Diretrizes e Base da Educação Nacional (LDBEN) no 4024/61, promulgada em 20 de dezembro de 1961. O ordenamento trata da finalidade, direito, administração, organização, profissionalização docente, sistemas de ensino entre outros temas e aborda a formação de docentes para o ensino primário, a partir do Curso Normal de formação de professores. De acordo com o dispositivo legal, a formação dar-se-ia no curso normal, conforme podemos ver nos seguintes artigos:

Art. 52. O ensino normal tem por fim a formação de professôres, orientadores, supervisores e administradores escolares destinados ao 21 ensino primário, e o desenvolvimento dos conhecimentos técnicos relativos à educação da infância.

Art. 53. A formação de docentes para o ensino primário far-se-á: a) em escola normal de grau ginasial no mínimo de quatro séries anuais onde além das disciplinas obrigatórias do curso secundário ginasial será ministrada a preparação pedagógica; b) em escola normal de grau colegial, de três séries anuais, no mínimo, em prosseguimento ao vetado grau ginasial.

Art. 54. As escolas normais, de grau ginasial expedirão o diploma de regente de ensino primário, e, as de grau colegial, o de professor primário.

Art. 56. Os sistemas de ensino estabelecerão os limites dentro dos quais os regentes poderão exercer o magistério primário.

A Lei $n^{\circ} 5692 / 71$ acaba por alterar o artigo $n^{\circ} 54$, facultando a oferta formativa para escolas públicas ou particulares (BRASIL, 1971), o que, de fato, demonstra o ajuste das políticas públicas às necessidades do capital privado. Esse processo é o início de todo o desmantelar da escola pública como lócus privilegiado de formação e educação.

A LDBEN no 4024 de 1961 apresentava parâmetros para a formação de professores nos diferentes níveis de ensino. O ordenamento continha ainda uma relação de revogações e vetos para o atendimento da população por meio da alfabetização, entretanto não apresentava diretivas sobre a formação dos que estariam aptos a lecionar nesses programas de alfabetização em massa. Vasconcellos (2016, p. 23) afirma:

Dessa forma se compararmos as duas leis, verificamos um retrocesso com relação às possibilidades formativas do professor contidas na Lei 4024/61, em detrimento de uma aceleração na formação de mão de obra para atingir um maior número de iletrados possível, com improviso formativo e aligeiramento na formação.

Aos poucos, o Curso Normal vai perdendo seu status de formador de uma carreira promissora, passando a representar uma habilitação conclusiva de $2^{\circ}$ grau (SAVIANI, 2009). O autor destaca que o movimento de desvalorização da formação para a docência está atrelado à mudança do currículo formativo mais característico para um currículo de núcleo comum a todos os cursos de $2^{\circ}$ grau, adicionando algumas disciplinas de caráter específico para a habilitação à docência, tendo tal organização prevalecido até a Lei de Diretrizes e Bases da Educação Nacional (LDBEN nº. 9394/1996)

onde após um amplo debate, com direito a posições tensas e opostas entre defensores da educação pública e representantes do ensino privado, os avanços almejados vieram de forma parcial e fragmentada. Reconhecemos os ganhos para os profissionais da educação em se tratando de nomenclatura e na preferência de formação inicial em nível superior, entretanto, as múltiplas formas e instituições formativas para o profissional docente tomaram uma proporção maior do que se imaginava (VASCONCELLOS, 2016, p. 24).

Nesse sentido, concordamos com Tardif (2002), ao afirmar que os saberes dos professores não se caracterizam como uma "construção individual", pelo contrário, constrói-se essa relação a partir das trocas com os demais pares, alunos e, acrescentamos, com a comunidade escolar, como um organismo complexo e em consonância de propósitos. 
No Brasil, com a atual LDBEN no 9.394, de 20 de dezembro de 1996, entra em vigor a habilitação para a docência, por meio da Graduação em cursos de Pedagogia, ofertados em instituições públicas ou privadas do país. Salientamos que a atual LDBEN, ao longo de seus 25 anos, continua a ser a legislação em vigor e tem sido constantemente alterada, perdendo assim, em muitos aspectos, a essência de inovação e, paradoxalmente, necessitando desses e de outros ajustes para que esteja de acordo com as inúmeras mudanças que ocorrem na sociedade e que influem diretamente na organização da educação. Ou seja, de fato, pensamos que já estamos em atraso com a necessidade de uma nova legislação que trate da formação para a docência e que esteja em consonância com as inúmeras mudanças sócio-políticaseducacionais e tecnológicas ocorridas ao longo das últimas três décadas.

As Diretrizes Curriculares Nacionais para os Cursos de Pedagogia (BRASIL, 2006) referendam a formação em curso de Licenciatura em Pedagogia para a formação de professores, a fim de que exerçam as funções de magistério em Educação Infantil e nos anos iniciais do Ensino Fundamental; habilita também para docência em cursos de Ensino Médio na modalidade Normal; de Educação Profissional e ainda em áreas de serviços e apoio escolar e em quais sejam previstos os conhecimentos pedagógicos (BRASIL, 2006, p. 2). Como já mencionado, em 2006, a Resolução $\mathrm{CNE} / \mathrm{CP} \mathrm{n}^{\circ}$ 01, de 15 de maio de 2006, instituiu as DCNs - Pedagogia com uma concepção ampliada de docência, que compreende o ensino, a pesquisa e a gestão. Em 2015, o Parecer CNE/CP n ${ }^{\circ} 02$, de 09 de junho de 2015, traz as Diretrizes Curriculares Nacionais para a Formação Inicial e Continuada dos Profissionais do Magistério da Educação Básica (CONSELHO NACIONAL DE EDUCAÇÃO, 2015). Em 2019, a Resolução n 2, de 20 de dezembro de 2019, define as Diretrizes Curriculares Nacionais para a Formação Inicial de Professores para a Educação Básica e institui a Base Nacional Comum para a Formação Inicial de Professores da Educação Básica (BNC-Formação).

Diante do atual cenário educacional brasileiro, torna-se inevitável a necessidade de uma reformulação dos cursos de formação docente para que proporcionem ao futuro profissional um aprendizado que compreenda a construção dos conhecimentos como fator essencial em sua formação integral como intelectual. No entanto, se não bastassem as questões estruturais desses cursos, tais como: asfixia de recursos, falta de motivação por parte de alunos e professores, infraestrutura deficiente etc., há como agravante a desvalorização econômica e social da figura do professor. Para tentar reverter tal situação, é preciso buscar uma política educacional que efetivamente valorize a formação do profissional da Educação em toda sua extensão, preconizando qualidade, salário e condições de trabalho dignas (BERNADO, 2015).

Temos evidenciado o dilema que persegue o professor da escola básica do século XXI por ser formado, como aluno e como professor, em uma escola reprodutivista, com um viés bancário (Bourdieu; Passeron, 2011; Freire, 2005), com uma rotina e um currículo formatados, baseados no paradigma positivista e, ao mesmo tempo, é desafiado ao trabalho em uma perspectiva em que os alunos estão embebidos em novas tecnologias da comunicação, emaranhados nas redes sociais (em seu melhor e em seu pior) e, em meio a esse cenário dúbio, precisa atuar como profissional docente. A ampliação das funções docentes, mais do que nunca, está atrelada a uma necessidade de buscar formação e orientação para o exercício da docência. E apesar de todas as dificuldades e do engessamento da estrutura escolar, sabemos da importância desse lócus privilegiado de circulação e de construção de saberes. Nesse sentido, concordamos com Bernado (2003, p. 73) ao afirmar que a

formação de professores nos remete a pensar a escola como espaço privilegiado de formação. Se nas instituições formais de ensino, o professor realiza sua formação inicial, seja ela em nível médio ou superior, na escola, local de trabalho do professor, ele encontra um espaço que promove sua formação continuada.

Sublinhamos que a formação inicial do indivíduo para a docência encontra-se amparada por ordenamento legal e que a sua construção identitária será uma construção elaborada ao longo do seu exercício profissional.

Sobre a Formação Inicial em Portugal e no Brasil, seja por um oceano que separa, pela diferença em tamanho ou por quantidade de anos de existência, a história de Brasil e Portugal funde-se de modo íntimo. Entre discursos de descobrimento ou de invasão, certo é que existem muito mais proximidades do que se pensava. No campo da educação não é diferente, temos vivido os desafios de 
construir e praticar um currículo na/da formação inicial que faça sentido aos estudantes das licenciaturas/mestrados integrados, de aumentar o tempo de prática, de vivências em lócus reais, apoio à prática investigativa da sua própria prática (FLORES, 2015; BODIÃO; FORMOSINHO, 2010). Defendemos um revisitar as didáticas de modo que essas se tornem navios que flutuem sobre novas e boas práticas e não âncoras que prendem e arrastam o que há no fundo, quando muito movendo areias de um lado ao outro.

Mais ainda que as diferentes, as normativas/diretrizes que formam o professor dos anos iniciais em Portugal e no Brasil retratam o modo e a visão político-educacional de ambos os países. Portugal, numa perspectiva de bloco pertencente à União Europeia, busca a valorização dentro dos apontamentos da OCDE (2016), Agenda 2030, dentre outros. O Brasil, por outro lado, tentando superar as disparidades sócio-económico-educacionais, numa via de globalização interna porque, de fato, o Brasil por si só já tem dimensão e profundidade de proporções continentais. O que de fato não podemos deixar de salientar são as lacunas entre teoria e prática e a falta de um projeto real que integre a universidade/centros de formação às escolas e, em conjunto, os estudantes, futuros professores, que almejam aprender na experimentação e vivência direta.

\section{INDUÇÃO NA PROFISSÃO DOCENTE: UMA REVISÃO SISTEMÁTICA DE LITERATURA}

Esta seção do artigo refere-se a uma Revisão Sistemática de Literatura com o foco em compreender a construção de conhecimentos e práticas nos primeiros anos da docência, por meio da participação dos sujeitos num estudo que busca tornar públicas as suas experiências, as suas próprias vozes e reconhecer que a identidade profissional, individual e coletiva se encontra em constante transformação/construção/refiguração de si e do outro.

A investigação enquadra-se num paradigma interpretativo, de abordagem qualitativa, na modalidade de pesquisa biográfica em educação. Associando as técnicas de análise documental e grupos reflexivos, pretendemos que a produção de dados/recolha de evidências com a perspectiva das histórias de vida e formação nos permitam prosseguir com uma investigação participante que valoriza a ética e as subjetividades na construção do conhecimento científico, ao mesmo tempo que relaciona investigação, ação e formação.

Para nossa investigação, identificamos a necessidade de realizar uma Revisão Sistemática de Literatura (RSL), uma vez que o campo temático escolhido situa-se na construção identitária do perfil de profissional docente. Diante disso, consideramos ser de fundamental apoio para o desenvolvimento deste trabalho investigativo a realização de uma RSL que contemplasse:

- O panorama das pesquisas realizadas sobre a construção da identidade docente;

- O contributo e as discussões teóricas sobre construção da identidade docente nos últimos

anos;

- As áreas mais discutidas e as que ainda continuam invisibilizadas (lacunas) pelas investigações científicas sobre esse perfil profissional, em especial, nas Ciências da Educação;

- Identificar, sintetizar e descrever os contributos que os estudos teóricos têm para oferecer a esta investigação e outras que se seguem.

A compreensão que temos sobre uma RSL está em concordância com a perspetiva de Ramos, Faria \& Faria (2014), ao ressaltarem que há uma ampliação de acesso e divulgação de artigos pelas vias mediáticas. Carvalho (2002, p.81) contribui para a discussão ao enfatizar que as Ciências da Educação são como "prolongamentos ou como aplicações especiais das diferentes Ciências Sociais e Humanas". Dessa forma, as Ciências da Educação pertencem a um domínio interdisciplinar no qual é "cada vez mais complexa a atividade de seleção, não só no momento da pesquisa (...) mas cima de tudo na determinação do que é ou não cientificamente credível” (RAMOS; FARIA; FARIA, 2014, p. 21).

Para além do que já discutimos, uma RSL organizada e desenvolvida criteriosamente valoriza o trabalho de quem realiza a investigação, tornando-a uma referência validada pela comunidade científica 
a qual pertence, abrindo possibilidade para outros pesquisadores continuarem a descobrir novos conhecimentos, favorecendo a produção de nas pesquisas, permitindo o avanço de uma rede interligada com a construção do outro como colaborador da nossa investigação.

De acordo com Gomes e Caminha (2014, p. 397), "revisões bem estruturadas podem auxiliar na atualização e construção de novas diretrizes para atuação profissional ou ida a campo em busca de soluções para artigos originais". Por não haver grande tradição da utilização de RSL nas Ciências da Educação, destacamos o que Ramos, Faria \& Faria (2014b, p. 19-20) expressam a esse respeito:

\begin{abstract}
Se bem que nem em Portugal nem no Brasil se conheçam ainda grandes avanços nesta área, propomos que a revisão sistemática de literatura seja aplicada às Ciências da Educação, como é noutras áreas do conhecimento. Deveremos, assim, procurar definir critérios, métodos precisos e sistemáticos, por forma a identificar e selecionar as fontes bibliográficas com o máximo rigor, grau de eficiência e confiança no trabalho desenvolvido.
\end{abstract}

Como a RSL em Ciências da Educação bebe da fonte inicial da área médica, empirista por natureza, a rigor, é importante para sua realização, a definição inicial de um protocolo, no qual sejam definidos: a pergunta inicial, quais serão os critérios tanto de inclusão como de exclusão de artigos de investigação, quais e como serão utilizadas as estratégias de recolha de dados e a análise do material identificado, como será realizada a produção de dados, a categorização, a análise, sistematização e relatório final com os resultados da pesquisa.

Para iniciar o protocolo da RSL, destacamos como questão de partida: Identificar os estudos que discutam o processo de entrada na profissão de educadores de infância e dos professores dos anos iniciais $/ 1^{\circ}$ ciclo. Com relação ao processo e as etapas contidas numa RSL, Ramos, Faria \& Faria (2014c, p. 23) ressaltam que no

processo de revisão sistemática de literatura, é imprescindível que sejam registadas todas as etapas de pesquisa, não só para que esta possa ser replicável por outro investigador, como também para se aferir que o processo em curso segue uma série de etapas previamente definidas e absolutamente respeitadas nas várias etapas.

Respeitamos o ponto de vista dos autores e, com base nas nossas práticas investigativas anteriores, afirmamos que as etapas previamente definidas, apesar de importantes, não garantem que sejam absolutamente respeitadas. É necessário ter em conta a efetiva participação dos diferentes intervenientes na investigação e os respectivos contextos.

É de suma importância que o pesquisador procure ter o máximo de clareza e transparência, não só no relatório de resultados, mas em todo o processo que antecede a sua finalização e reflexões conclusivas. Para tanto, exemplificamos como se deu o processo de nossa RSL, partindo da construção do protocolo da RSL que realizamos e ensejamos que tal partilha oportunize novas reflexões e apontem direções epistemológicas que nos auxiliem no trilhar dessa seara.

\title{
Quadro 1: A construção do protocolo
}

\begin{tabular}{|l|l|}
\hline Objetivo da revisão & $\begin{array}{l}\text { Identificar o que dizem os estudos acerca o período de entrada na } \\
\text { profissão de professores. }\end{array}$ \\
\hline Questão & $\begin{array}{l}\text { O que revelam os estudos sobre o período de entrada na profissão de } \\
\text { professores? }\end{array}$ \\
\hline Período: & 2007-2019 \\
\hline Bases de dados: & RCAAP, B-On, Scielo, Web of Science \\
\hline $\begin{array}{l}\text { Combinação de palavras- } \\
\text { chave: }\end{array}$ & $\begin{array}{l}\text { Profissão Docente; } \\
\text { Indução; } \\
\text { Entrada na Profissão; } \\
\text { Carreira Docente; }\end{array}$ \\
\hline
\end{tabular}




\begin{tabular}{|l|l|}
\hline & $\begin{array}{l}\text { Educadores; } \\
\text { Professores; } \\
\text { Mentor educacional. }\end{array}$ \\
\hline Critérios de inclusão: & $\begin{array}{l}\text { Artigos académicos, com revisão por pares, indexados em periódicos } \\
\text { reconhecidos; } \\
\text { Escrito em Português, Espanhol, Inglês. }\end{array}$ \\
\hline Critérios de exclusão & $\begin{array}{l}\text { Teses }{ }^{3} \text { de mestrado; } \\
\text { Escritos em idioma diferente dos acima descritos; } \\
\text { Atas de Congressos, Seminários, Simpósios, Encontros; } \\
\text { Textos cujo enfoque seja a epistemologia de construção do } \\
\text { conhecimento disciplinar. }\end{array}$ \\
\hline
\end{tabular}

Fonte: As autoras.

Inicialmente, enfatizamos que a construção da pergunta de partida se deu no intuito de levantar textos que abordassem a entrada na profissão dos Educadores/Professores oriundos dos cursos de Mestrado em Educação Pré-escolar e Primeiro Ciclo do Ensino Básico em Portugal. Desse modo, alargamos nossa busca ao percebermos que tal campo de estudo tem sido objeto de algumas pesquisas em andamento, sem, contudo, apresentar uma literatura vasta e consolidada a qual pudéssemos recorrer.

Quanto ao recorte temporal, destacamos que o perfil profissional que se consolida como objeto de nossa investigação, análise e reflexão, só passa a existir pós-processo de Bolonha, o que nos remete ao recorte a partir de 2007. Assim sendo, após a organização e definição dos critérios do protocolo da RSL, selecionamos artigos que continham uma ou mais palavras-chave, combinadas ou não. Obtivemos, inicialmente, 147 artigos publicados em periódicos de acordo com os critérios de inclusão descritos no protocolo.

Dessa totalidade, após a leitura das palavras-chave e dos resumos, realizamos a exclusão de 115 artigos, dentre os quais: 28 abordavam a formação inicial de professores de educação básica; 15 referiam-se aos estágios e práticas de ensino, mas no âmbito do processo de formação inicial; 34 artigos abordavam a formação continuada de professores; 8 apontavam a formação de professores do ensino superior; 12 discutiam formação de professores de áreas específicas ou para atuação em nível secundário; 8 tratavam das narrativas de alunas em formação e, finalmente, 10 referiam-se à legislação, à política e ao currículo de formação, entretanto sem referência direta à entrada dos professores na profissão.

A partir dessa primeira exclusão, ficamos com um número de 32 artigos para serem lidos e analisados. Após uma leitura minuciosa desses artigos, realizamos uma segunda exclusão de mais 2 textos e, justificamos para tanto, o facto de, apesar de fornecerem alguma aproximação com a questão de partida de nossa RSL, tais textos não forneciam informações e contributos de forma direta. Desse modo, ao acreditarmos que toda leitura produz em nós conhecimento e enriquece nosso arcabouço conceptual, a exclusão dos artigos que nessa fase da investigação não teriam relação direta com a questão de partida do nosso protocolo de RSL não invalida o fato de que, com a leitura de 32 artigos na íntegra, retivemos alguns conceitos que em outros momentos poderão nos ajudar na reflexão, na crítica e na escrita.

Os resultados e discussões que a partir de agora apresentamos são dos 30 artigos restantes dessa seleção e que produziram nossa reflexão sobre a questão: O que revelam os estudos sobre o período de entrada na profissão de professores? Olhando o recorte temporal em nossa investigação, podemos inferir que a partir de 2015, os estudos sobre indução/iniciação na carreira docente aparecem em mais estudos. Quanto ao conteúdo discutido nos textos, variam no enfoque, abordando desde as políticas públicas de indução na carreira docente até as memórias de professoras em seu primeiro ano de efetivo exercício da profissão.

\footnotetext{
${ }^{3}$ Em Portugal os trabalhos de conclusão do Mestrado são denominados Teses, diferente do Brasil que nomeia por Dissertação.
} Educação em Revista|Belo Horizonte|v.37|e32800|2021 
Com relação às Políticas Públicas de Indução, a revisão apresentou estudos realizados em países como: México, Brasil, República Dominicana, Argentina, Finlândia, Portugal, Chile, Peru, Colômbia, Espanha e França. Nesses estudos, os autores destacam que as organizações de Programas Oficiais de Indução estão fortemente relacionadas à agenda de organismos multilaterais, reforçando a crença da educação (formação inicial, período de indução na carreira e formação contínua) como ferramenta preciosa para a melhoria dos índices e da qualidade do ensino (FLORES, 2015; CORDEIRO; JÍMENEZ, 2018; MARCELO; VAILLANT, 2017; SANCHÉZ; RODRÍGUES, 2016).

Ressaltamos que, alguns artigos trouxeram conceitos e dados muito importantes e que nos ajudaram a perceber que não há um modelo padrão para a construção da identidade docente. Diferentes formações, diferentes currículos, diferentes pessoas, logo, diferentes formas de ser e estar/entrar na profissão. Como exemplo, trazemos o caso da Finlândia (NIEMI, 2015) quando aponta que o desenvolvimento profissional dos futuros docentes começa na própria formação e que para além de tal percepção, os futuros professores mantêm o foco na investigação como produtora de conhecimento. Logo, ser um profissional docente está diretamente ligado com ser um pesquisador de sua própria formação e de sua futura prática.

O estudo comparado realizado por Sanchéz \& Rodriguez (2016) conservam a fórmula de quadro comparativo entre dois países europeus (Espanha e França) e dois países sulamericanos (Colômbia e Argentina), destacando que o treinamento para ser professor, de acordo com a Comissão Europeia/EACEA/Eurydice(2013), pode ocorrer de forma simultânea à própria formação ou consecutiva, após a formação.

Com relação à construção de apoio ou melhoria da prática nos primeiros anos da docência, Marcelo \& Vaillant (2017) ressalta a urgência de pensar e implementar programas de indução para professores ingressantes, aborda a tutoria como recurso, mas toca no ponto do acolhimento e reflete sobre relação desigual e de status quo entre professores já pertencentes ao quadro e os "novatos". O autor avança na proposta de uma construção vertical dentro de uma lógica de diálogo e troca de saberes e experiências.

Alguns trabalhos apresentaram a indução como um hiato, um vazio a ser visibilizado. Nóvoa (2019, p. 199) apresenta a indução como «O tempo mais importante na nossa constituição como professores, na construção da nossa identidade profissional». E, nesse sentido, outros autores inseridos nesta revisão sistemática de literatura trouxeram as vozes de professores principiantes para descreverem o que sentiram e como experienciaram esse período de tornarem-se docentes em exercício.

A partir das pesquisas de Bodião \& Formosinho (2010); Roldão \& Alarcão (2014), temos descritas as primeiras experiências na docência de professoras em Portugal, como: angustiantes, isoladas, permeadas de postura de reforço da hierarquia (os mais antigos escolhem as turmas primeiro, os principiantes ficam com as turmas consideradas mais difíceis), pouca ou nenhuma ação de integração entre os principiantes e os mais experientes, sem nenhuma organização de atividades em conjunto entre pares, para planear, partilhar vivências, entre outros. Os autores também ilustram o início da carreira de forma a comparação de: "ser lançado às feras", "ser atirado para a selva", "desbravar o terreno".

Outros autores destacaram em seus textos reflexões de cunho epistemológico sobre a construção da identidade docente, profissionalidade docente, conhecimento docente, prática docente, saber profissional docente, ação profissional, correlacionando tais dimensões conceptuais ao período de indução docente (GUERREIRO; RIBEIRO, 2015; FLORES, 2015; GORZONI; DAVIS, 2017; ROLDÃO; ALARCÃO, 2014).

Retornando ao conceito de indução, ele aparece em alguns textos desde os anos de 1990, com o ciclo de vida profissional apresentado por Huberman (1992) que dividia o tempo de docência em 5 etapas, sendo elas: entrada na profissão, estabilização, diversificação do repertório, serenidade, desinvestimento. De outra forma, Marcelo $(2009 ; 2010)$ apresenta uma nova interpretação em 4 fases: pré-treino ou formação, a formação inicial, a iniciação profissional e a formação permanente. Já Nóvoa (1992) resume esse ciclo a 3 fases: formação inicial, indução profissional e formação continuada, sendo com essa última organização em etapas, que mantemos nossa aproximação teórica. Nóvoa (2019) reforça, ainda, que a entrada na profissão é um período que necessita de um olhar atento e denomina esse momento de «entre dois». É o momento que separa a formação inicial da profissão de fato. É o rito de passagem de discente a docente. 
Como descobertas, nomeadamente, podemos destacar:

- O período de indução docente ganha novos olhares das políticas educativas a partir das demandas das agendas mundiais, atribuição da melhoria da qualidade de ensino por meio da educação/formação;

- O período de indução como um ato solitário, de incertezas, período de abandono da carreira; tais aspectos são sinalizados como "falta de casca", ou seja, o professor principiante fica muito dependente dos conteúdos, ainda não sabe improvisar, não tem repertório, prática ou segurança para diversificar (ROLDÃO, 2009).

- As iniciativas de indução nos países estudados descritos nos artigos evidenciam uma lógica formativa voltada para a prática (técnicas de ensino) em detrimento de uma formação acolhedora, com trabalho colaborativo, criando laços entre pares;

- Um período de indução bem elaborado permite o empoderamento do professor principiante, colaborando na sua construção identitária;

- Experiências na investigação-formação têm-se mostrado eficazes para o preparo do professor iniciante, mas isso não basta! É preciso desconstruir a cultura que segmenta e hierarquiza os profissionais por antiguidade ou tempo de exercício da prática docente.

- Um período de acompanhamento e apoio ao desenvolvimento do trabalho e práticas integrativas que fortaleçam e integrem o novo profissional à cultura e ao cotidiano da escola são efetivamente o que buscam os novos profissionais.

$\mathrm{Na}$ próxima seção, trazemos as contribuições da formação continuada na trajetória profissional docente.

\section{FORMAÇÃO CONTINUADA: O QUE APRENDEMOS COM/NA INVESTIGAÇÃO?}

A última parte de nosso artigo refere-se à uma pesquisa realizada nos anos de 2015/2016 que buscou, ao longo de seu desenvolvimento, investigar um novo projeto de educação integral no município de Niterói, no estado do Rio de Janeiro/Brasil. O principal objetivo dessa investigação consistiu em analisar as percepções dos professores com relação à formação continuada oferecida pela rede municipal de educação com vistas ao fortalecimento da educação em tempo integral Niterói/RJ. Ao longo de nossa pesquisa, dialogamos com diversos autores dedicados à temática do tempo integral, tais como: Coelho (2009; 2013), Cavaliere (2015), Bernado (2003; 2015).

Buscamos ainda, em nosso estado da arte, suporte conceitual por meio das leituras dos estudos e pesquisas que tratavam de questões centrais para nossa construção teórica, destacando: a construção das questões de profissionalização docente e reflexibilidade da ação docente, amplamente estudadas por Huberman (1992), Nóvoa (1992), Tardif \& Lessard (2005), Gatti et al (2011), entre outros. Para desenvolvermos o trabalho, realizamos uma pesquisa bibliográfica e documental acerca das temáticas formação docente, educação integral e educação em tempo integral no Brasil, debruçando-nos de fato sobre as experiências de Anísio Teixeira com o Centro Educacional Carneiro Ribeiro, dos Centros Integrados de Educação Pública (CIEPs) nos anos de 1980 e 1990 aos dias atuais.

A pesquisa realizada enquadrou-se na modalidade estudo de caso, com viés qualitativo e utilizou a análise descritiva de um questionário preenchido pelos professores e as entrevistas semiestruturadas realizadas com os membros responsáveis pela elaboração, formalização e implementação da proposta desse modelo específico de tempo-espaço-currículo diferenciado de todo o conjunto de outras quarenta e sete escolas da mesma rede de educação. Esse grupo de estudiosos recebeu o nome de Comissão Dácio Tavares Lobo Júnior. Participaram da pesquisa dezenove professores que se identificaram como sendo cinco do sexo masculino e catorze do sexo feminino. Já em relação à faixa etária, temos a seguinte organização: um professor na faixa etária de até 24 anos; dois professores entre 25 e os 29 anos; oito encontram-se na faixa dos 30 aos 39; 4, sendo um professor na faixa etária dos 40 aos 49 anos, um professor entre 50 e 54 anos e dois professores acima dos 55 anos de idade. Um professor optou por não responder essa questão.

A questão que nos moveu foi compreender se e como os momentos de formação continuada promovidos pela rede municipal de educação de Niterói ou pela própria escola, lócus do processo de 
nosso estudo e as formações continuadas ofertadas aos docentes modificavam e/ou influenciavam suas práticas nesse modelo de escola em tempo integral.

Os participantes da pesquisa, ao longo do processo, foram observados e responderam a um questionário com questões semiestruturadas, em que puderam descrever, por meio de algumas questões abertas, seus pensamentos, opiniões, sugestões, receios, dúvidas e desapontamentos. Esse retorno foi de extrema importância e tem se voltado para a rede de educação e para os profissionais participantes na forma de publicações de artigos de revista e de capítulos de livro.

A título de ilustrar a importância da escuta das vozes dos sujeitos participantes sobre os contributos da formação continuada, apresentaremos um excerto no qual era perguntado ao professor participante como ele via a formação continuada que acontecia dentro da escola, às quartas-feiras, no horário das 15 horas até as 17 horas.

O fato de já estar no local de trabalho ajuda. Nos sentimos mais à vontade para falar, tirar dúvidas. Quando é em outro local, não gosto de falar. Fico só ouvindo. Muitas vezes, não me diz nada. (Professor 4)

Outro participante, um membro da Comissão que elaborou a proposta de escola de tempo integral e que foi entrevistado para a pesquisa, apresenta uma fala que vai na direção da necessidade de mais tempo para que esse professor se sinta mais preparado para atuar de acordo com essa diretriz.

É. Eu acho que o professor que está vivenciando essa... esse modelo, ele precisa de mais. Só essas duas horas, não são suficientes, eu penso isso. Eu penso que elas são importantes, elas são fundamentais, porque uma escola de educação integral tem que começar pela integração entre os membros que estão ali dentro. Então, estas duas horas de formação às quartas-feiras é fundamental. Agora, eles precisam de mais [...] (Entrevistado 2)

Então, pensamos acerca do que seria enfim a formação continuada. Para além das muitas expressões individuais que carregam uma visão de mundo particular, existem as definições conceituais de autores-pesquisadores da área e, em nosso trabalho, identificamo-nos com a definição de Bragança e Perez (2016, p. 1165):

\begin{abstract}
tomamos a expressão formação continuada, justamente, por sua dimensão alargada, incluindo os direcionamentos institucionais, encaminhados pelos sistemas de ensino, ou seja, instituídos, bem como aqueles movimentos que se dão de forma capilar, miúda, a contrapelo, produzidos pelos professores/as que produzem as práticas pedagógicas nas escolas de tempo integral, dando a essas práticas múltiplos sentidos.
\end{abstract}

As conclusões e achados de pesquisa confluíram para um reconhecimento e valorização dos momentos formativos, não só pela potência a nível de conhecimentos teóricos e de novas construções práticas, como também pelo fator de aproximação humana que tais momentos oportunizavam, fortalecendo o conjunto de profissionais, docentes ou não docentes como um corpo pedagógico em harmonia com os interesses dos alunos e da comunidade escolar. Tal movimento permitiu que se verificasse, no cotidiano escolar, uma série de boas e inovadoras práticas pedagógicas que transbordavam em forma de projetos, quer individuais (por turma) ou institucionais, por meio de parcerias, como por exemplo, no caso do Programa Interinstitucional de Bolsas de Iniciação à Docência (PIBID/Pedagogia/UFF).

Apesar dos pontos positivos que destacamos, a pesquisa também revelou desafios muito particulares no que tange à efetivação de um projeto de escola em tempo integral, apontados pelos participantes, dentre os quais destacamos: formação insuficiente para superar os desafios de uma escola de tempo integral; a importância de garantir os tempos e espaços das formações continuadas oferecidas dentro da unidade escolar; a necessidade de uma maior quantidade de profissionais para cobrir a demanda da escola de tempo integral e a urgência de repensar os tempos formativos desses profissionais dentro e fora do espaço escolar. 


\section{CONSIDERAÇÕES FINAIS: (IN) CONCLUSÕES E PROVOCAÇÕES DE UMA INVESTIGAÇÃO...}

Professores bem preparados, com autonomia, trabalhando juntos dentro e fora do espaço escolar, no relacionamento com as famílias são sempre a melhor garantia de soluções oportunas e adequadas. O reforço do profissionalismo dos professores é fundamental. Devemos investir na formação de professores e em políticas curriculares que garantam e reconheçam a autonomia docente. Precisamos fortalecer a capacidade de ação e colaboração profissional dos

(Nóvoa; Alvim, 2020)

Essa epígrafe, por si só, já seria suficiente para encerrar este texto e nos deixar inquietos, a pensar de que maneiras havemos de seguir e construir novos caminhos e possibilidades formativas com nossos estudantes de graduação, que ambicionam, após a conclusão da formação inicial, sua entrada na docência e que esse início do exercício da docência corra bem. A reflexão abarca também aqueles que participam em nossas pesquisas, narrando suas primeiras experiências profissionais ou ainda aqueles que já contribuíram, por meio de suas vozes polifônicas, em trabalhos já concluídos, reafirmando a importância de se saber sempre mais.

Quiçá, teremos apresentado a esses algum repertório que provoque novas experimentações em seu fazer cotidiano e que construa suas identidades, individuais e de grupo, sua profissionalidade e caráter ético, tão necessários em todas as profissões e imprescindíveis na docência.

Neste texto, buscamos costurar algumas reflexões que nos acompanham ao longo de mais de duas décadas de trabalho em docência, seja em nossas formações iniciais, nos primeiros anos da docência ou como investigadoras de nossas próprias práticas nos ensinos básico e superior.

O fato é que o ciclo formativo do professor está cada vez mais ligado a um movimento em forma de espiral hermenêutica (SUAREZ, 2017), em que intercala-se a tríade a formação-reflexão-ação, como pilar da sua construção identitária individual (a pessoa do professor), da sua construção coletiva (a identidade do grupo profissional docente) ou ainda, a construção e pertença a um coletivo comunitário, que atravessa as duas primeiras construções, conjugando-o como sujeito complexo, dotado de múltiplas capacidades e competências.

O professor é o profissional metamorfo que se adapta às condições que lhe são ofertadas e, nesse contexto, precisa estar receptivo à formação constante, seja para aperfeiçoamento, melhoria, ou aquisição de novos conhecimentos. Parte importante da formação docente é compreender que seu trabalho necessita dessas e de muitas outras e novas competências para acontecer. Ter a consciência desse processo é fundamental para que continue a trabalhar e investir na construção de uma identidade profissional sólida e consistente com seu esforço e dedicação.

A formação inicial precisa incluir em seu currículo a importância da pesquisa da sua própria prática e o reconhecimento de si como produtor de saberes. A entrada na profissão deve se debruçar sobre políticas e programas de recepção e integração, um verdadeiro sistema de apoio para o profissional iniciante se sentir integrado ao coletivo e os profissionais que já estão no processo há alguns anos devem ser valorizados, escutados, desafiados a continuar investindo em sua formação, como uma mais-valia para si e para os seus alunos.

\section{REFERÊNCIAS}

BERNADO, E. (2003). Formação continuada de professor em escolas organizadas em ciclo.106 f. Dissertação (Mestrado em Educação) - Programa de Pós-Graduação em Educação, Pontifícia Universidade Católica do Rio de Janeiro, Rio de Janeiro.

Técnico do $\overline{\text { SENA }}$ C, Rio de Janeiro.

(2015). Formação Docente: que tipo de intelectual queremos formar? Boletim

BERNADO, E. S.; VASCONCELLOS, K. R. T. (2017). Formação continuada em uma escola de tempo integral: notas sobre um estudo de caso. Contrapontos (Online). , v.17, p.744 - 760.

BODIÃO, I. S.; Formosinho, J. (2010). A profissionalidade docente na educação básica em Portugal: depoimento de alguns professores. Educação e Pesquisa, 36 (1), pp. 403-418. São Paulo. 
BOURDIEU, P.; PASSERON, J. C. (2011). A Reprodução: Elementos Para uma Teoria do Sistema de Ensino. Petrópolis, Vozes.

BRAGANÇA, I. F. DE S. ; PEREZ, J. G. (2016). Formação Continuada em Escolas de Tempo Integral: narrativas de professoras. Educação \& Realidade, Porto Alegre, 41(4), pp. 1161-1182, out./dez. 2016.http://dx.doi.org/10.1590/2175-6236606

BRASIL. Lei de Diretrizes e Base de nº1961 - Lei 4024/61 Lei de Diretrizes e Base de no 5.692, de 11 de agosto de 1971

Lei $\mathrm{N}^{\circ}$ 9.394, de 20 de dezembro de 1996. Estabelece as diretrizes e bases da educação nacional. Diário Oficial da União, Brasília, DF, 23 dez. 1996. Disponível: Acesso em: 15 jul. 2015.

CANÁRIO, R. (2012). Formação e desenvolvimento profissional dos professores. Disponível: https://crispasuper.files.wordpress.com/2012/06/formdesenvolprofisprofes.pdf

CARVAlHO, A. (2002). Epistemologia das Ciências da Educação. (4Ed.). Porto: Edições Afrontamento

CAVALIERE, A. M. et ali. (2015). Educação integral e educação do corpo na obra de Anísio Teixeira. In: Currículo sem Fronteiras, v. 15, n. 2, p. 527-542, maio/ago. 2015 - ISSN 1645-1384 (online) www.curriculosemfronteiras.org 527

COELHO, L. M.C. (2009). Educação Integral em tempo integral: estudos e experiências em processo. Rio de Janeiro. . (2013). Educação Integral: história, políticas e práticas. Rio de Janeiro: Rovelle.

CORDERO, A.G.; JIMÉNEZ, J. A. (2018). La Política de Ingreso a la Carrera Docente en México: Resultados de una supuesta Idoneidad. Archivos Analíticos de Políticas Educativos. AAPE/EPAA, 26 (5), pp. 1-27.

FLORES, A. (2015). Formação Docente e Identidade Profissional: Tensões e (des)continuidades. Educação[impresso], 38(1), pp. 138-146.

FREIRE, P. (2005). Pedagogia do oprimido. Rio de Janeiro: Paz e Terra. Unesco: Brasília.

GATTI, B.; Barreto, E.; André, M. (2011). Políticas docentes no Brasil: um estado da arte.

GOMES, I. E CAMINHA, I. (2014). Guia para estudos de revisão sistemática: uma opção metodológica para as Ciências do Movimento Humano. Revista Movimento, Porto Alegre, 20(1), pp. 395-411.

GORZON, S.P.; DAVIS, C. (2017). O conceito de profissionalidade docente. Cadernos de Pesquisa, 47(166), pp. 1396-1413.

GUERRERO, L. S.; RIBEIRO, M. R. (2015). El conocimiento profesional como característica distintiva de profesionalización docente en la formación de profesores. Revista Iberoamericana de producción Académica e Gestión Educativa. 2, pp.1-19

HUBERMAN, M. (1992). O ciclo de vida profissional dos professores. In A. Nóvoa (Org.), Vidas de professores. pp.31-62 Portugal, PT: Porto Editora.

LEAL DA COSTA, C.; SARMENTO, T. (2018). Escutar as crianças nos anos iniciais e afirmar a nossa identidade profissional. Revista Educação em Análise, 3(2), pp.72-94.

MARCELO, C. (2009). Desenvolvimento profissional docente: Passado e futuro, Sísifo Revista de Ciências da Educação, 8(1), 7-22.

(2010). O professor iniciante, a prática pedagógica e o sentido da experiência. Formação Docente, 2(3), 11-49.

MARCELO, C.; VAILLANT, D. (2017). Políticas y Programas de Indocción en la docencia en Latinoamérica. Cadernos de Pesquisa 47(166) pp. 1224-1249.

MONTERO, L. (2001). A Construção do Conhecimento Profissional Docente. Instituto Piaget, Lisboa - PT.

NIEMI, H. (2015). Teacher Professional Development in Finland: Towards a More Holistic Approach. Psychology, Society, \& Education, Vol. 7(3), pp. 279-294.

NÓVOA, A. (1992). Os professores e a sua formação. Lisboa: D. Quixote, (2019). Entre a Formação e a Profissão: ensaio sobre o modo como nos tornamos professores. Currículo sem Fronteiras. 19(1), pp. 198-208. 
NÓVOA, A., ALVIM, Y. (2020). Nada é novo, mas tudo mudou: Um olhar sobre a escola do futuro. Prospects 49(1), pp. 35-41.

NUNES, S., LEAL DA COSTA, C. (2016). Tornar-se Educadora/Professora - Palavras que contam como foi! Educação e Contemporaneidade, 25 (47), 119-136.

PORTUGAL. Decreto-Lei 43/2007, 2007-02-22 - DRE

RAMOS, A.; FARIA, P. \& FARIA, A. (2014). Revisão sistemática de literatura: contributo para a inovação na investigação em Ciências da Educação. Revista Diálogo Educacional, 14(41), pp.1736.

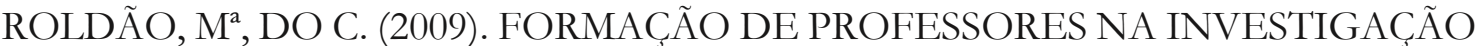
PORTUGUESA - UM OLHAR SOBRE A FUNÇÃO DO PROFESSOR E O CONHECIMENTO PROFISSIONAL. Form. Doc., 1(1), pp. 57-70.

ROLDÃO, Ma ${ }^{a}$, DO C., ALARCÃO, I. (2014). Um passo importante no Desenvolvimento Profissional dos Professores: O Ano de Indução. Form. Doc., 6(11), pp. 109-126.

SANCHÉZ, J.; RODRÍGUES, M. (2016). Iniciación Del Desarrollo Profesional De Los Docentes De Educación Primaria (Argentina, Colombia, España Y Francia). Estudio Comparado. Cuestiones Pedagógicas, 25(1), pp. 23-36.

SAVIANI, D. (2009). Formação de Professores: aspectos históricos e teóricos do problema no contexto brasileiro. Revista Brasileira de Educação 14(40). pp.143-155

SUAREZ, D. (2017). Relatar la experiencia docente. La documentación narrativa del mundo escolar. Conversas sobre formação de professores, práticas e currículos. Revista Teias. 18(50), pp.193209.

TARDIF, M. (2002). Saberes docentes e formação profissional. Petrópolis: Vozes.

TARDIF, M.; LESSARD, C. (2005). O trabalho docente: elementos para uma teoria da docência como profissão de interações humanas. Petrópolis: Vozes.

UNESCO (2016). Repensar a educação: rumo a um bem comum mundial? Brasília. http//unesdoc.unesco.org/images/0024/002446/244670POR.pdf

VASCONCELLOS, K. (2016). Formação Continuada na Escola Municipal Anísio Teixeira: Um olhar sobre a formação docente. Dissertação de Mestrado - Universidade Federal do Estado do Rio de Janeiro - UNIRIO - Rio de Janeiro, 137 fls.

VASCONCELLOS, K. R. T.; BERNADO, E. S. (2016). Profissionalização docente: reflexões e perspectivas no Brasil. Educação \& Formação. , v.1, p. 208 - 222. . (2016). Formação docente e tempo integral: um olhar sobre a formação continuada da Escola Anísio Teixeira. Cadernos ANPAE. , v.1, p. 1051 - 1065.

Submetido: $30 / 03 / 2021$

Aprovado: 01/09/2021 